\title{
BILINGUAL EDUCATION IN HONG KONG
}

In Corson, D. \& Cummins J. (Eds.) (1997). Encyclopedia of Language and Education, Volume 5: Bilingual Education (pp. 281-289). The Netherlands: Kluwer Publications.

By Angel Mei Yi Lin

City University of Hong Kong

Hong Kong

Hong Kong exemplifies a special case in which the notions of 'bilingual education' and 'dominant language background' take on non-conventional meanings. First, only the immersion approach to bilingual education is officially accepted and bilingual classroom practices have been discouraged by the Hong Kong government as educationally unsound (Education Commission 1990, 1994, 1995). Government policies notwithstanding, Cantonese-English bilingual classroom practices are prevalent, albeit officially illegitimate, in what are nominally English medium secondary schools/universities. Second, although Cantonese is the mother tongue and the dominant, daily life, language of the majority of people in Hong Kong, English is the politically and socioeconomically dominant language.

\section{Early Developments}

Since Hong Kong was ceded by Dynastic China to Britain as a colony in 1842, vernacular or Chinese medium education (usually practised as Cantonese in speaking and Modern Standard Chinese in writing) has received little government support. By 1911, the government was providing an English medium education up to university level for children largely from well-to-do families, and a vernacular primary education for children from less well-to-do families (Irving 1914). In 1935, a British education inspector, Burney, visited Hong Kong and completed the famous Burney Report (1935), in which he criticized the Hong Kong government for neglecting vernacular education. However, government resources continued to be channelled mainly to English medium schools, cultivating a Westernized, English-conversant elite among the local Chinese population (see historical documentation by Fu 1975). Despite the lack of government support, in the period between the consolidation of the Chinese Nationalist Government in China in 1928 and its retreat to Taiwan in 1949, private Chinese medium schools rapidly outnumbered English medium schools in Hong Kong due to the influence and support of institutions in China (see historical documentations by Cheng 1949; Wong 1982). However, after 1949, with the People's Republic of China adopting a largely selfisolationist stance towards Hong Kong and the rest of the world, Chinese medium schools declined in popularity in Hong Kong because there no longer existed an alternative, attractive symbolic market offering higher studies and job opportunities for Hong Kong Chinese medium school graduates. By the 1980s, $90 \%$ of secondary school students in Hong Kong studied in English medium schools (see historical documentation by So 1992). 


\section{Major Contributions}

In 1973, Cheng, Shek, Tse and Wong highlighted the educational problems created among Chinese children by English medium secondary school education in Hong Kong with their paper, 'At what Cost?'. They surveyed 170 Cantonese-speaking firstyear university students, half of whom had just completed secondary education in the English medium. Seventy-three percent of these students thought that using English as the medium of instruction imposed a heavy burden on them, and yet 54\% said they would still choose English medium. In 1979, Siu and his colleagues published their research report on the effects of the medium of instruction on students' cognitive development and academic achievement, demonstrating the superior effects of using Chinese rather than English as the medium of instruction for students with below average academic ability. Both Cheng et al (1973) and Siu et al (1979) argued for the need to inform the public about the benefits of mother tongue education.

In 1981, the government commissioned a team of visiting, foreign experts to undertake a review of the education system in Hong Kong. The resulting Llewellyn Report (1982) highlighted the problems created by large-scale English immersion in what is de facto, although not de jure, still a monolingual society:

It is the form rather than the substance that still counts in Hong Kong where one is subject to the spectacle of a born-and-bred Hong Kong speaker of Cantonese going through the ritual of instructing Cantonese-speaking pupils by means of a language in which both teacher and taught have little competence. (Llewellyn et al, 1982, p. 28)

The Llewellyn Report suggested that the crux of the matter of English medium education is bound up with social status and labour market appeal. It recommended that the government should embark on a long-term project of changing parents' and employers' attitudes towards Chinese as a teaching medium by providing more resources to Chinese medium schools and by offering a quota to assure a proportion of admissions from Chinese medium secondary school graduates to higher study and the Civil Service. It also suggested that the government could, alternatively, acknowledge the reality of widespread bilingual oral practices in the classrooms of nominally English medium schools and to make serious attempts to improve the effectiveness of this reality by developing genuinely bilingual curriculum strategies.

The first recommendation was not taken up by the government in any serious manner, but the second recommendation can be seen to be embodied in Johnson's studies on classroom bilingual teaching strategies (Johnson 1983) and the effectiveness of various oral and written modes of presentation (Johnson, Chan, Lee \& Ho, 1985). In the first study (Johnson 1983), it was found that teachers systematically code-switched between Cantonese and English for different purposes. In general, English was found to be associated with text-dependent, formal and didactic functions; whereas Cantonese was 
found to be associated with text-independent, informal and explanatory functions. In his conclusion, Johnson wrote:

Separation of the languages is one simple, but possibly also simplistic, approach to the problems of bilingual education, and I am not convinced that there is anything intrinsically wrong with code-switching in bilingual classrooms. At the very least, the teaching strategies identified here are capable of greater sensitivity to differences amongst learners and groups of learners than the separation approach. (Johnson, 1983, p. 282)

In the second study, Johnson et al (1985) tested for the effects of different linguistic modes of presentation and questioning on the subsequent comprehension test scores among 1,296 Form 3 (Grade 9) students. It was found that irrespective of the linguistic mode of presentation of the texts, students scored higher on average when answering Chinese questions, and irrespective of the linguistic mode of questioning, students scored higher on average when the texts had been presented in the Cantonese mode or the bilingual mode. When asked about their preferences on the medium of instruction, less than 3\% of the 1,296 students preferred English-only instruction. In the oral mode, the students were about equally split in their preference for Cantonese-only instruction or Cantonese-English bilingual code. In the written mode, over $70 \%$ of the students preferred to study with Chinese texts, although $11 \%$ would also like to have English glosses added to the Chinese text, and 32\% would also like to have a corresponding English text side by side with the Chinese text. Apparently, the majority of students preferred a bilingual to an English-only mode of instruction.

The bilingual approach to the medium of instruction was, however, challenged in a paper by Swain (1986). Having visited Hong Kong and reviewed the school language situation in Hong Kong, Swain concluded with the following recommendations:

To conclude, what I am suggesting is that positive intervention needs to occur in the medium of education issue in Hong Kong. The mixing of languages that exists in most Hong Kong secondary schools serves neither the goal of academic achievement nor second language learning to maximum effectiveness. An English medium option can be highly effective in both, and can be justified if it offers both. Thus, in order to provide the necessary conditions for a successful English medium stream, enrollment should be limited to students who have achieved high levels of cognitive academic proficiency in Chinese and who have demonstrated a level of English adequate for being able to profit from instruction in it. (Swain, 1986, p. 6)

Swain (1986) put forward the maximum exposure hypothesis and the threshold hypothesis as theoretical grounds for the separation approach to bilingual education in Hong Kong. These have subsequently constituted the rationale for the linguistic streaming policy recommended by the Education Commission (1990, 1994, 1995). Since September 1994, the Hong Kong government has adopted the policy of classifying all Hong Kong secondary schools into three groups: EMI, EMI/CMI and CMI based on their students' English and Chinese scores. Schools classified as EMI are advised to use only 
English as the medium of instruction. Schools classified as CMI are advised to use only Chinese (taken as Cantonese in speaking and Modern Standard Chinese in writing) as the medium of instruction. Schools classified as EMI/CMI are advised that they can choose between an English-only or Chinese-only medium of instruction. However, the majority of existing 'English medium schools' which have been advised to switch to CMI continue to call themselves `English medium schools', while in reality continuing to operate in a Cantonese-English bilingual oral mode and an English written mode.

To understand this paradox, Lin (1996) closely analysed instances of classroom Cantonese-English code-switching and delineated various bilingual discourse formats that seemed to serve a variety of sociocultural, educational or linguistic brokering functions. Situating those linguistic brokering classroom practices in their larger embedding historical and socioeconomic context, Lin argued that these practices were the teachers' and students' local, pragmatic, coping response to the symbolic domination (Bourdieu 1982/1991) of English in Hong Kong, where many students from socioeconomically disadvantaged backgrounds with limited access to English resources struggled to acquire an English medium education for its socioeconomic value. This analysis builds on earlier perspectives expressed in So $(1984,1992)$ and Yau (1988). In addition, Lin showed that the special kind of bilingual practices witnessed in Hong Kong classrooms did not seem to support the development of bilingual academic competence but seemed to have the effect of perpetuating the ideological domination of `English academic monolingualism' in Hong Kong (Lin, 1996, p. 70). By delineating the organizational features of these discourse practices, Lin showed that they neither affirmed the value, nor supported the development, of Chinese academic literacy. These 'English medium schools' were shown to be, after all, orienting to norms of English academic monolingualism, albeit operating with a bilingual mode for expediency.

\section{Work in Progress}

In a preliminary report, Chan in consultation with Johnson and Hoare (1996) reported on the first-year findings of an on-going two-year study of the effectiveness of English medium instruction in 59 secondary schools in Hong Kong. The majority of these schools claimed to use EMI in all or most subjects. While no school explicitly claimed to use a bilingual oral mode, the study found that most of the EMI schools operated with a bilingual oral mode and the amount of English used varied with the academic ability of the students in different classes, even within the same school. It also varied with the nature of the academic subjects, and with the different functions being performed by teachers and students. For example, teachers reported using more English in the English language lessons than in the Math and Science lessons; students tended to use most English in answering teachers' questions but least English in talking to one another. We can see from this finding that teachers' classroom code choice seemed to be sensitive both to the academic ability of students and to the specific nature of different academic subjects, and students apparently had strong preferences for interacting with one another in their mother tongue rather than in English. The classroom participants 
seemed to refuse to have their code choice pre-determined by the label or the linguistic policy adopted by the school authorities.

The study also found that the correlation between the amount of English reported to be used in the classroom and the students' progress in English performance was not particularly high. The researchers thus mentioned the importance of qualitative factors (e.g., the ways in which English was used in the lessons), which they intend to study in the following year.

Another study, which focuses on the cognitive and affective effects of using English and Chinese to different extents as instructional languages in Form 1 (Grade 7) in 24 secondary schools in Hong Kong, is now being conducted by Tung and his colleagues.

Among the 24 participating schools, 12 claim to use EMI, 4 CMI, 3 EMI in some subjects and CMI in the other subjects, and 5 have separate EMI and CMI streams within the same school. The attainment test scores at the end of the first year of the study show that schools adopting the partial immersion mode (i.e., with some subjects in EMI and some in CMI) seem to be doing better academically than schools in the EMI or CMI mode. Also, although their English attainment average gain score is slightly lower than that of the EMI schools, it is much higher than that of the CMI schools. In addition, their Chinese attainment average gain score is much higher than that of both the EMI and CMI schools (Tung, personal communication, June 1996). One probable explanation for the favourable attainment results of the partial immersion schools can be that the partial immersion mode supports the cognitive academic literacy development of students in both their Chinese and English, and the students' first language and foreign language academic literacy skills might have been mutually supportive and enhancing.

Tung and his colleagues also surveyed over 5,000 students and over 4,600 parents of these 24 schools in 1995. The reported findings (Tung, Tsang \& Lam, 1997) indicate that both parents and students believe that English medium education brings about a better standard of English and favour English medium education for the socioeconomic importance of English. However, students also support a gradual transition from Chinese to English as the medium of instruction, and are in favour of the teacher using both English and Chinese in the same lesson. In contrast, both parents and teachers tend to express the view that teachers should not teach in both English and Chinese in the same lesson.

Problems, Difficulties, and Future Directions

The teachers' expressed negative view towards the bilingual medium seems to be in contradiction to their actual classroom practices. It seems that teachers might experience some conflict between what they believe to be (officially) correct to do and what they find necessary to do in situ. This seems to be a common predicament experienced by many teachers in Hong Kong since the expansion of formerly elitist secondary education in the late 1970s. The unfavourable attitude towards bilingual 
classroom practices expressed by parents and teachers might have been a result of the official, academic, and media discourses which claim that bilingual classroom practices have negative educational results (see critical analysis by Lin, 1997).

The mismatch between what is officially correct to do and what teachers actually find it necessary to do in the classroom is not restricted to the secondary sector but has been increasingly witnessed and documented in the tertiary sector since the expansion of formerly elitist university education in the late 1980s in Hong Kong (e.g., Walters \& Balla, 1992; Flowerdew, Li \& Miller, 1996). The major dilemmas and difficulties facing us can be summarized as follows:

(1) The majority of people in Hong Kong have limited access to English resources as they live in a largely monolingual lifeworld where English does not play an important communicative role, and where sociocultural norms mediate against the use of English among Chinese sharing a common first language.

(2) After the universalization of formerly elitist secondary education in the late 1970s, and the expansion of formerly elitist university education in the late 1980s, the majority of students, and teachers to a lesser extent, do not have enough English resources to learn and teach entirely in English. Many English immersion secondary schools and universities have, to varying extents, shifted to a Cantonese-English bilingual oral medium while maintaining an English written medium and striving to maintain the socioeconomically prestigious label of `English medium schools/universities'. Despite increasing government pressure on the majority of secondary schools to switch to Chinese medium, most schools defy government advice because of the great popular, societal, and job market demand for English medium education even on the eve of 1997, when Hong Kong will rejoin China as a Special Administrative Region.

(3) The recent official policy of banning bilingual classroom practices in Hong Kong has made teachers generally unwilling to bring their actual classroom practices into the open and few research efforts are/can be made to examine these practices to explore their educational potential and to improve and develop them to be an alternative, legitimate, effective approach that supports the academic literacy development of students in both Chinese and English.

(4) The lack of official support for alternative bilingual approaches, e.g, partial immersion (with some subjects taught in English and some in Chinese), bilingual medium (e.g., using bilingual texts), has made it difficult to research the viability of alternative approaches which may be more suited to the needs of the majority of Hong Kong students, who cannot be expected to jump the gap between their Cantonese home world and their English immersion school world without suffering educationally. Total English immersion has not been viable and has never actually been implemented in the majority of nominally English medium schools due to the factors mentioned in (1) and (2) above. However, the local, pragmatic, expedient bilingual classroom practices in these schools do not seem to support the development of Chinese academic literacy, and 
students continue to resort to rote memorization and copying to cope with the English written work and examinations in these schools.

It can be seen that Hong Kong people have been placed in dilemmas that have arisen from the socioeconomic dominance of English over a largely monolingual, Cantonese-speaking population. If Chinese-English bilingual literacy development among the majority of students is a genuine, worthwhile goal for the people of Hong Kong, the Hong Kong government needs to assign more resources to teachers' bilingual and bi-literacy development. We also need to develop viable bi/tri/multi-lingual education approaches that will enable the majority of students to bridge the multiple linguistic gaps between their home world and their school world: the gaps between their mother tongue (Cantonese) and Chinese literacy, between Cantonese and spoken English,

and between Chinese literacy and English literacy. Daunting as the task appears to be, the bi/tri/multi-lingual experiences of other places as documented in other articles in this volume testify to the great educational potential of various multilingual approaches. Future research work in Hong Kong needs to take seriously these alternative approaches and explore their potential for the majority of Hong Kong students, and not only for the elitist few who can benefit from total English immersion.

(2932 words)

\section{REFERENCES}

Bourdieu, P.: 1982/1991, Language and Symbolic Power (G. Raymond \& M. Adamson, Trans.). Cambridge University Press, Cambridge, Mass. (Original work published 1982). Burney, E.: 1935, Report on Education in Hong Kong. Government Printer, Hong Kong. Chan, A., Johnson, K. \& Hoare, P.: 1996, A Study of English Medium Instruction in Secondary 1 in Hong Kong Schools: Preliminary Report of the First Year of a HongkongBank Language Development Fund Project. HongkongBank Language Development Fund, Hong Kong.

Cheng, N. L., Shek, K. C., Tse, K. K. \& Wong, S. L.: 1973, At what cost?--Instruction Through the English Medium in Hong Kong Schools. Shum Shing Printing Company, Hong Kong.

Cheng, T. C.: 1949, The Education of Overseas Chinese: A Comparative Study of Hong Kong, Singapore and the East Indies. Unpublished M.A. thesis, London University. Education Commission: 1990, Education Commission Report No. 4. Government Printer, Hong Kong. Education Commission: 1994, Report of the Working Group on Language Proficiency. Government Printer, Hong Kong.

Education Commission: 1995, Education Commission Report No. 6. Government Printer, Hong Kong.

Flowerdew, J., Li, D. C. S. \& Miller, L.: 1996, Attitudes Towards English as the Medium of Instruction Among Hong Kong Chinese University Lecturers. Report submitted to the City University Quality Assurance Committee.

Fu, G. S.: 1975, A Hong Kong Perspective: English Language Learning and the Chinese Student. Unpublished doctoral dissertation, University of Michigan. 
Irving, E. A.: 1914, The Educational System of Hong Kong. Government Printer, Hong Kong.

Johnson, R. K., Chan, R. M. L., Lee, L. M. \& Ho, J. C.: 1985, An Investigation of the Effectiveness of Various Language Modes of Presentation, Spoken and Written in Form III in Hong Kong Anglo-Chinese Secondary Schools. Education Department, Hong Kong Government.

Johnson, R. K.: 1983, `Bilingual Switching Strategies: A Study of the Modes of TeacherTalk in Bilingual Secondary School Classrooms in Hong Kong', Language Learning and Communication 2, 3, 267-283.

Lin, A. M. Y.: 1996, `Bilingualism or Linguistic Segregation? Symbolic Domination, Resistance, and Code-Switching in Hong Kong Schools', Linguistics and Education 8, 1, 49-84.

Lin, A. M. Y.: 1997, `Analysing the "Language Problem" Discourses in Hong Kong: How Official, Academic, and Media Discourses Construct and Perpetuate Dominant Models of Language, Learning, and Education', Journal of Pragmatics. Llewellyn, Sir John et al: 1982, A Perspective on Education in Hong Kong: Report by a Visiting Panel. Government Printer, Hong Kong.

Siu, P. K. et al: 1979, The Effects of the Medium of Instruction on Student Cognitive Development and Academic Achievement: Final Report. School of Education, Chinese University of Hong Kong.

So, D. W. C.: 1984, The Social Selection of an English-Dominant Bilingual Education System in Hong Kong: An Ecolinguistic Analysis. Unpublished doctoral dissertation, University of Hawaii.

So, D.: 1992, 'Language-Based Bifurcation of Secondary Education in Hong Kong', in K. K. Luke (ed.), Issues of Language in Education in Hong Kong, Linguistic Society of Hong Kong, Hong Kong, 1992, 69-96.

Swain, M.: 1986, 'Two Ingredients to the Successful Use of a Second Language as a Medium of Instruction in Hong Kong', Educational Research Journal 1, 1-6.

Tung, P., Tsang, W. K. \& Lam, R.: 1997, `English as a Medium of Instruction in Post1997 Hong Kong: What Students, Teachers, and Parents Think', Journal of Pragmatics. Walters, S. \& Balla, J.: 1992, English Medium Instruction at City Polytechnic of Hong Kong. Research Report No. 17, Department of English, City Polytechnic of Hong Kong. Wong, C. L.: 1982, A History of the Development of Chinese Education in Hong Kong. [in Chinese]. Po Wen Book Co, Hong Kong.

Yau, M. S.: 1988, `Bilingual Education and Social Class: Some Speculative Observations in the Hong Kong Context', Comparative Education 24, 2, 217-228. 